\title{
Parental Income and Children's Smoking Behaviour: Evidence from the British Household Panel Survey ${ }^{*}$
}

\author{
Laura Blow, Andrew Leicester and Frank Windmeijer \\ Institute for Fiscal Studies
}

May 2005

\begin{abstract}
Does money matter? When investigating health behaviour, research often finds a strong positive association between income and healthy behaviour. This could however be due to individual characteristics that determine both income and health investment and is not necessarily due to the role of money per se. In this study we look at this relationship over the generations by studying the association between parental income and children's prevalence to smoke in Britain using data from the British Household Panel Survey and British Youth Survey. We find an inverse relation between parental income and children's smoking prevalence, but when looking at within household changes by comparing sibling's smoking status differences at the same age, we find instead a positive effect. This indicates that within household increases in income lead to an increased probability of smoking of a younger child.
\end{abstract}

Key Words: Child smoking, Parental income, Panel Data

JEL Classification: I12, C23

\section{Introduction}

Since coming to power in 1997, the UK Government has shown much concern about the prevalence of smoking amongst young people. A 1998 White Paper, Smoking Kills, set out a target to reduce smoking rates amongst 11 to 15 year olds from $13 \%$ in 1996 to 9\% or less by 2010. In 2004, a second White Paper, Choosing Health: Making healthy choices easier, also expressed concern about “... the number of children and young people who take up smoking” and proposed greater penalties for

\footnotetext{
* Acknowledgements: Financial support from the HM Treasury Evidence Based Policy Programme and the ESRC Centre for Economic Evaluation, grant no. H141251024, is gratefully acknowledged.
} 
shopkeepers illegally selling cigarettes to children under the age of 16 . The most recent Government figures for 2003 suggested that the smoking rate had fallen to 9\% as quickly as 1999 but that since then the rate had stabilised at between $9 \%$ and $11 \%$.

Obviously if there is an explicit aim to reduce the extent of smoking amongst children, insight is necessary into what factors may influence the decision of young people to smoke or not. Ease of access to cigarettes - whether from retailers or other family members - may clearly be one factor, as might advertising, peer pressure and so on. There has been extensive research into the factors influencing adult smoking behaviour which shows that smoking depends on education and income, and specifically that low income/education individuals smoke more. It may therefore be that whether a child smokes or not also depends on the income of the parents, perhaps directly or indirectly. If the children of smokers are themselves more likely to smoke, then low parental income may make the parents and therefore the children more likely smokers. This paper aims to investigate the influence of household incomes on children’s smoking behaviour.

A relatively large body of literature has emerged looking at the impact of various factors on children's smoking behaviour, such as peer smoking, parental smoking, anti-smoking advertising and attitudes to smoking. Although parental socio-economic status has formed a large part of the analysis, the studies have tended to focus on parental education and class information rather than parental income information directly (see Tyas and Pederson (1998) for a review of the literature). A study by Soteriades and DiFranza (2003) uses either household income or parental education as a proxy for socio-economic status and find a significant inverse relationship of these with adolescent smoking, after controlling for various other confounders, like adult smoking status and disposable income of the child. In their paper, Soterides and Difranza (2003) also review numerous studies that investigate the relationship between parental socio-economic status and children's smoking behaviour. Whereas Tyas and Pederson (1998) conclude that there exists an inverse relationship, Soterides and Difranza (2003) found various studies that did not find a significant association.

In our analyis we will first of all contribute to this debate by investigating the extent of an inverse association of parental socio-economic status and adolescent smoking in Britain using longitudinal data from the British Household Panel Survey. Our focus 
will be particularly on the role of parental income and we will further try to establish whether there is a causal link by investigating differential behaviour within households by siblings that could be attributed to changes in household income.

Since 1994, the British Household Panel Survey (BHPS) has contained a section aimed at children aged 11 to 16 in each sample household. This relatively unexploited $^{1}$ source of information contains direct questions about the child's smoking habits, and forms the basis of our research. The panel element of the data is especially useful in trying to identify the effects of income on smoking since it allows us to employ fixed effects techniques to strip out constant factors of a particular family which might be correlated with incomes but exert an independent influence on smoking behaviour (which would tend to bias any impact of income in a simple OLS regression). In particular, we examine differences in the smoking behaviour of siblings when they reach the same age and how these compare to income differences in the household at the time the siblings reach a particular age. Using these techniques, we suggest that the effect of parental incomes on children's smoking behaviour is small, but if anything the relationship is positive: a higher within household income increases the likelihood of a child being a smoker.

Various economic studies have investigated the responses of young people to cigarette prices and other public policy effects, see e.g. DeCicca, Kenkel and Mathios (2002), Ross, Chaloupka and Wakefield (2001) and Gruber (2000). Interestingly, Gruber (2000) actually finds an inverse relationship between price responsiveness of adolescents and the socio-economic status of their parents. In this study we will not focus on price responsiveness, although prices of cigarettes have increased substantially over the observation period. This was due mainly to the large duty increases that were imposed by successive chancellors. The way these and other public policy effects are being controlled for in our study is by incorporating flexible

\footnotetext{
${ }^{1}$ Ermisch, Francesconi and Pevalin (2001) use these data for an analysis of poverty dynamics. Brynin (1999) uses four waves of the youth data from the BHPS to look at how various factors influence smoking behaviour amongst children. Using logistic regression to look at the influence of these factors on the decision of children either not to smoke, to 'dabble' in smoking or to smoke regularly, he suggestes that it may be differences in self-esteem and beliefs about the dangers of smoking which leads to different choices being made and finds no role for family income, or indeed family background more widely.
} 
time effects in the models. In Banks, Blow and Windmeijer (2005), the price responsiveness is investigated using the BHPS adult sample (16 years and older).

The paper is organised as follows. Section 2 discusses the data used to address the questions in hand and looks at some broad trends in smoking rates amongst children. Section 3 analyses the impact of household income on youth smoking in a simple probit framework, before section 4 extends the analysis to consider sibling differences. Section 5 concludes.

\section{Data}

Our data is taken from the British Household Panel Survey (BHPS) between 1994 and 2001 (waves four to eleven). In 1994, the BHPS included for the first time a separate questionnaire for children aged 11 to 15 in each sample household. This is known as the British Youth Panel (BYP). Use of this data allows us to determine whether children are smokers based on their own admission rather than whether or not their parents believe their children to smoke. Whilst there may be obvious concerns about children accurately reporting their smoking behaviour, the children's surveys are designed to be fully confidential, with the questionnaire being completed independently by the child using questions taped on a personal headset rather than answering directly to an interviewer. We are then able to supplement this BYP data with information from the main BHPS about the family circumstances. As it is a panel survey, we can also track some of the children as they move beyond age 16 and become members of the main adult survey in the BHPS itself - we continue to track children up to the age of 18.

A variety of questions are asked in the BYP about both the child's smoking behaviour and their attitudes towards smoking in general. We use two variables to determine whether or not a child should be defined as a smoker. First, "How many cigarettes did you smoke in the last seven days?”. If the child reports at least one, we define them as a smoker. If they report zero in the last week, they may still be classed a smoker if they then self-categorise themselves as someone who sometimes smokes but not every week, which is a possible response to a second question in the BYP which asks about how often the child smokes. For those children that are tracked into the adult survey, 
we can use their response to the direct question of whether or not they categorise themselves as a smoker.

Because the BHPS does not interview each household at the same time in each year, there are cases where we do not observe household members ageing between surveys, or where they appear to age by more than one year. To circumvent this, we re-define the age of the children as the age at which we first observe them plus the difference between the survey year and the survey year in which we first observe them.

After removing cases where interviews were completed by proxy or were incomplete, we have 7,288 observations of 2,467 unique children. Of these children, we need to define cases where we can find two siblings that we can observe at the same age in the data at different points in time (in order to generate differences in household incomes) $)^{2}$. This gives 1,951 observations of 751 unique children in this "sibling sample”. This is made up of 814 pairs of siblings (1,628 observations), 105 cases where there are three siblings that reach the same age at different points (315 observations) and 2 cases where there are four siblings (8 observations). Because our fixed effects model will look at differences between siblings, when there are more than two siblings we can make more than one comparison. In these cases, we compare each younger sibling to the eldest.

For the descriptive information below, however, we focus on a slightly restricted sample derived from the "core” BHPS data only. In 1997, extra data was added to the sample from the European Community Household Panel (ECHP) which overrepresents low income people. From 1999, extra observations were also included for Scotland and Wales, and from 2001 for Northern Ireland, to allow separate analyses of these regions to be carried out. We are able to control for income and region in our regression results in sections 3 and 4, such that including these additional observations ought not to bias our results, instead introducing greater precision in our estimates by increasing the sample size. However, including them in the descriptive statistics below would not be appropriate since low income households and households in different regions are likely to exhibit different smoking behaviours. Restricting attention for the moment to the core BHPS sample means we can get a picture of

\footnotetext{
${ }^{2}$ This restriction means we exclude twins, triplets etc from our sibling subsample.
} 
smoking behaviour that is nationally representative. This restricted sample contains 5,957 observations of children, 1,836 of which are included in the sibling sub-sample.

The tables below give some descriptive statistics about smoking behaviour from our sample. In each case, the left-hand panel shows results for the whole sample of data and the right-hand panel the sibling sample alone.

Table 1. Smoking prevalence across time

\begin{tabular}{c|cc|cc}
\hline Year & $\begin{array}{c}\text { Full Sample: } \\
\text { \% of children } \\
\text { smoking }\end{array}$ & Observations & $\begin{array}{c}\text { Sibling Sample: } \\
\text { \% of children } \\
\text { smoking }\end{array}$ & Observations \\
\hline 1994 & 10.0 & 600 & 8.1 & 197 \\
1995 & 15.7 & 649 & 13.0 & 208 \\
1996 & 17.1 & 725 & 16.0 & 213 \\
1997 & 18.2 & 780 & 16.7 & 246 \\
1998 & 17.2 & 829 & 14.0 & 279 \\
1999 & 16.1 & 777 & 14.9 & 242 \\
2000 & 15.2 & 798 & 16.7 & 233 \\
2001 & 14.4 & 799 & 13.8 & 218 \\
\hline
\end{tabular}

Table 1 displays the adolescent smoking prevalence across the observation years. Smoking amongst children appeared to become slightly more prevalent through the latter 1990s than in the mid-1990s before rates began to fall away again around the turn of the century. Given the relatively small numbers of children, particularly in the sibling sample, it is unlikely that the year-on-year differences in smoking rates are statistically significantly different from one another, however. There is no obvious explanation for the low rates observed in 1994.

Table 2 shows the smoking prevalence rates by age of the child. These figures suggest that smoking is rare amongst children up to the age of around 12. After that, smoking tendencies increase fairly rapidly such that by the time they become of legal age to purchase cigarettes, perhaps a quarter of children are already smokers. Beyond that, smoking rates tend to rise again, perhaps reflecting the fact that once it is legal to 
purchase cigarettes, smoking becomes a more attractive choice for some children who do not partake before legal age. ${ }^{3}$

Table 2. Smoking rates by age of child

\begin{tabular}{c|cc|cc}
\hline Age $^{4}$ & $\begin{array}{c}\text { Full Sample: } \\
\text { \% of children } \\
\text { smoking }\end{array}$ & Observations & $\begin{array}{c}\text { Sibling Sample: } \\
\text { \% of children } \\
\text { smoking }\end{array}$ & Observations \\
\hline \hline 11 & 1.8 & 1,027 & 1.3 & 449 \\
12 & 4.9 & 994 & 3.6 & 390 \\
13 & 11.2 & 907 & 11.1 & 333 \\
14 & 23.3 & 862 & 26.3 & 300 \\
15 & 28.1 & 745 & 33.8 & 198 \\
16 & 22.0 & 486 & 37.5 & 16 \\
17 & 31.0 & 407 & 41.5 & 53 \\
18 & 33.0 & 364 & 37.3 & 83 \\
\hline
\end{tabular}

The broad trends match the results from the most recent UK Department of Health (DoH) figures. ${ }^{5}$ In 2001, using the figures in the DoH data, smoking rates for boys rose from $1 \%$ at 11 to $5 \%$ at 13 and $19 \%$ at 15 . For girls, the increase was from $1 \%$ to $8 \%$ and 25\% respectively. Obviously breaking down the BHPS sample such that we can more directly compare our figures to the DoH figures results in much smaller cell sizes which would place more uncertainty around our estimates; further, the DoH definition of a smoker is a child that "normally smokes one cigarette or more a week" which is not directly attainable from the BHPS figures (where the question specifically refers to the previous week). Making such a comparison is therefore very difficult. Our best estimate is that the BHPS figures tend to produce higher smoking tendencies than the DoH, perhaps because our definition also includes children who

\footnotetext{
${ }^{3}$ The decline in smoking rates at age 16 in the full sample may be an artefact of the move from the BYP to the main BHPS at that age. The BHPS question to adults simply asks them to categorise themselves as a smoker or otherwise; it may be that people who smoke very infrequently would choose not to self-declare as a smoker even though we would be able to pick this up in the Youth Panel.

4 "Age" refers to the physical age of the child at the time of the BHPS interview rather than the constructed age discussed earlier in the section. Although the BHPS youth data is meant to be restricted to children aged 11 to 15 , there are small numbers of children observed at age 10 . We do not show them here since none of them smoked.

5 “Drug use, smoking and drinking among young people in England in 2003”, op. cit.
} 
self-define as a regular smoker even if they didn't smoke in the week prior to interview.

Table 3. Smoking rates by household income decile

\begin{tabular}{c|cc|cc}
\hline Income Decile $^{6}$ & $\begin{array}{c}\text { Full Sample: } \\
\text { \% of children } \\
\text { smoking }\end{array}$ & Observations & $\begin{array}{c}\text { Sibling Sample: } \\
\text { \% of children } \\
\text { smoking }\end{array}$ & Observations \\
\hline \hline 1 & 15.4 & 559 & 16.2 & 222 \\
2 & 17.2 & 500 & 17.2 & 186 \\
3 & 15.9 & 497 & 15.7 & 153 \\
4 & 17.3 & 678 & 17.1 & 228 \\
5 & 14.9 & 757 & 10.6 & 245 \\
6 & 14.8 & 819 & 12.1 & 240 \\
7 & 14.4 & 771 & 10.5 & 210 \\
8 & 14.8 & 583 & 16.0 & 169 \\
9 & 16.0 & 475 & 16.3 & 98 \\
10 & 17.9 & 318 & 12.9 & 85 \\
\hline
\end{tabular}

Table 3 breaks down the smoking prevalence rate by household income decile. These figures broadly suggest that smoking rates are higher for the richest and the poorest households, and lower around the middle of the income distribution. This is especially clear in the full sample; amongst the sibling sample a similar picture emerges though the numbers are more volatile.

\section{Youth smoking and household socio-economic status}

In this section we address the issue whether there is an inverse relationship between parental socio-economic status and youth smoking status. We estimate simple probit equations for smoking participation of the child to establish whether there is a household socio-economic status gradient in the children's smoking participation. We use household equivalised income and mother's education level to ascertain this gradient. As mentioned in the previous section, in this analysis we use all available data from the BHPS that also includes the observations from the European

\footnotetext{
${ }^{6}$ The income deciles are defined by taking household real equivalised income and dividing the data into ten equally sized groups from poorest to richest. Deciles are calculated from the whole sample of BHPS data, not just those households that have observations in the youth panel. This is the reason why there are no equal numbers of observations in each decile in our sample.
} 
Community Household Panel (ECHP) that over-represents low income people, and the extra observations from Scotland, Wales, and Northern Ireland later in the period.

Table 4 presents the estimation results for three separate models. In the first model we include household income (quintiles) as an explanatory variable, but not mother's education. In the second model we also include mother's education level, MEduc. ${ }^{7}$ The third model further includes an indicator variable whether there is an adult in the household that smokes. All models further include indicators for year, age, gender, region, number of children below 5 years old and between 5 and 11 years old, and mother's age.

In the model without the mother's education level, it is clear that there is an association with household income and the child's smoking status. Children from households with income within the first two quintiles are more likely to smoke than children from household in the top three quintiles. The reported coefficients can be translated into increased probabilities. For example, at the probability of smoking equal to 0.16 (the average smoking participation in the sample), the probability of smoking increases to 0.21 when moving from the fourth quintile to the first quintile of the household income distribution, which is a substantial increase.

When the mother's education level is included in Model 2, the pattern of the income effect remains the same, but the magnitudes for the first two quintiles, relative to the $4^{\text {th }}$ quintile, decrease and their estimated effects are now no longer statistically significant at the $5 \%$ level. There is a clear gradient in the effect of mother's education on their children's smoking status with children of mothers with lower education having a higher probability to smoke (with the exception of the highest educated, MEduc1, whose children are as likely to smoke as the excluded category, MEduc5).

When the presence in the household of an adult smoker is added to the model, the income effects get further reduced for the first two quintiles. The gradient associated

\footnotetext{
${ }^{7}$ The education variables denotes the highest level obtained and is recorded in 7 classes: $1=$ Higher Degree, $2=1^{\text {st }}$ Degree, 3 = HND, HNC, Teaching, $4=$ A Level, $5=$ O Level, $6=$ CSE, $7=$ None.
} 
with mother's education remains, but is also somewhat diminished in magnitude. The effect of parental smoking is large: at the average probability of 0.16 , the presence of an adult smoker in the household increases the probability of a child smoking to 0.29 .

Table 4. Probit estimation results for smoking participation.

\begin{tabular}{|c|c|c|c|c|c|c|}
\hline Variable & \multicolumn{2}{|c|}{ Model 1} & \multicolumn{2}{|c|}{ Model 2} & \multicolumn{2}{|c|}{ Model 3} \\
\hline & coeff & rob se & coeff & rob se & coeff & rob se \\
\hline Incq1 & $.2000^{* *}$ & .0792 & .1233 & .0802 & .1046 & .0816 \\
\hline Incq2 & $.1703^{* *}$ & .0743 & .1129 & .0757 & .0801 & .0768 \\
\hline Incq3 & .0256 & .0656 & -.0123 & .0663 & -.0163 & .0674 \\
\hline Incq5 & -.0177 & .0856 & .0418 & .0851 & .0795 & .0850 \\
\hline MEduc1 & & & .0262 & .2285 & .1962 & .2416 \\
\hline MEduc2 & & & -.2135 & .1555 & -.1558 & .1566 \\
\hline MEduc3 & & & $-.3509^{* *}$ & .1608 & -.2591 & .1617 \\
\hline MEduc4 & & & -.0862 & .1014 & -.0299 & .1001 \\
\hline MEduc6 & & & .1024 & .1017 & .0902 & .1030 \\
\hline MEduc7 & & & $.2101^{* * *}$ & .0749 & $.1789^{* *}$ & .0752 \\
\hline adsmoker & & & & & $.4451^{* * *}$ & .0591 \\
\hline $\log L$ & \multicolumn{2}{|c|}{-2623.17} & \multicolumn{2}{|c|}{-2597.84} & \multicolumn{2}{|c|}{-2539.79} \\
\hline $\begin{array}{l}6,997 \text { obser } \\
\text { reported in } \\
\text { Reported st } \\
\text { models are i } \\
\text { and } 11 \text { year }\end{array}$ & moth & tom & (n) & match & $\begin{array}{l}\text { lumber } \\
\text { ted age } \\
\text { regres } \\
\text { year ol }\end{array}$ & $\begin{array}{l}\text { ervations } \\
5 \text { ) is } 10 . \\
\text { all three } \\
\text { etween } 5\end{array}$ \\
\hline
\end{tabular}

It is clear from this analysis that there is an inverse association between parental socio-economic status and children's smoking prevalence, but that the income gradient is dominated by education gradient and that the effect is further diminished by parental smoking status. As adult smoking is inversely related to household income and education in this BHPS sample (see Banks, Blow and Windmeijer (2005)), it is clear that a large part of the relationship between children's smoking behaviour and parental socio-economic status is transmitted via the smoking status of the adults. ${ }^{8}$

\footnotetext{
${ }^{8}$ For a sub-sample of the children, we have further information about their own disposable weekly income. Results are not very different for Model 3 for this sub-sample when this disposable income is further added to the model. Own disposable income has a significant positive effect on smoking prevalence.
} 


\section{The effect of household income, sibling differences}

Does money matter? The results in the previous section made clear that children from poorer households are more likely to smoke, but that this effect was attenuated when controlling for parental education and smoking status of adults in the household. It is therefore clear that household income is correlated with other household specific factors that determine the smoking behaviour of the child and that it may not be money itself that drives observed behaviour.

To study the potential income effect in greater detail and to establish whether there is a possible causal relationship between parental income and smoking behaviour of the child, we next present results of an analysis where we use differences in smoking status between siblings within a household to determine an income effect. For example, the oldest sibling may be a smoker at age 15 in 1994 and her three year younger sibling may not be a smoker at age 15 in 1997. We will investigate whether this difference in smoking status is in any way related to the change in household income between the years 1994 and 1997, of course controlling for other factors that may have changed over time. By focusing on sibling differences within the household, we implicitly control for household characteristics that do not change over time, like mother's education. For a review of using sibling differences to identify causal effects see Griliches (1979) and for an application of an evaluation of Head Start in the US, see Garces, Thomas and Currie (2002).

Table 5 shows the estimation results for the sibling differences regression. The dependent variable (diffsmoke) is the difference in smoking status between the younger and oldest sibling in the household at the same age of the two siblings. This variable can therefore take the values -1 (younger sibling does not smoke, but older sibling does), 0 (both siblings smoke or both siblings do not smoke) and 1 (younger sibling smokes but older sibling does not). For the 1030 sibling pairs that can be identified in the data ${ }^{9}$, we observe for 73 cases (7\%) that the younger sibling does not smoke whereas the older sibling does, and for 99 cases (9.6\%) that the younger sibling smokes whereas the older sibling does not. If increases in household income

\footnotetext{
${ }^{9}$ That is, the 814 cases with two siblings, plus two observations each from the 105 cases of three siblings (comparing in turn the younger two with the eldest) and three observations each from the 2 cases of four siblings.
} 
have a negative effect on the smoking propensity of the children we would expect a negative coefficient in the regression of the sibling differences in smoking status on changes in household income. The results in Table 5 show a different picture. The income effect when estimating the model by OLS is positive and small, with an estimated value of 0.041 and standard error of $0.024 .^{10}$

Household income is likely to be measured with error. In a model using differences of income as an explanatory variable, the usual attenuation bias may be exacerbated because of the fact that the influence of measurement error becomes more severe when taking differences. We therefore also present results for an instrumental variables/GMM estimator, where food expenditures in the two different time periods are instruments for the income changes. The GMM results also show a positive relation between income and smoking status, the estimated coefficient being larger, 0.13 , but with a much larger standard error of 0.09 .

Table 5. Sibling differences estimation results, dependent variable diffsmoke

\begin{tabular}{|l|r|r|r|r|}
\hline & \multicolumn{2}{|c|}{ OLS } & \multicolumn{2}{|c|}{ GMM } \\
\hline & coeff & rob se & Coeff & rob se \\
\hline difflnincome & $0.0406^{*}$ & 0.0242 & 0.1337 & 0.0915 \\
\hline & & & & \\
\hline $\begin{array}{l}\text { Number of observations (sibling pairs) } 1030 \text {. Other variables included in the model are year indicators, } \\
\text { age indicators, gender and gender difference indicators, the age of the mother and the difference in age } \\
\text { of the siblings. The instruments for the change in log household income for the GMM estimation are } \\
\text { the log of expenditures on food in the two periods. The test for overidentifying restrictions does not } \\
\text { reject the validity of these instruments (p-value }=0.19) .^{*}: \text { significant at the } 10 \% \text { level. }\end{array}$ \\
\hline
\end{tabular}

Combining these results with the ones in the previous section we can conclude that, although one can find an inverse relationship between household income and children's smoking status as depicted in Model 1 in Table 4, this association cannot be translated in a causal relationship. As the results in Table 5 show, an increase in household income does not diminish the chance of a child in the household to become

\footnotetext{
${ }^{10}$ This result is robust to further including indicators for whether there is a difference in the adult smoking status between the years. These indicators are not significant in the regression. When the subsample of sibling pairs is analysed that have information on their own weekly disposable income, the coefficient on log household income differences drops to 0.022 and is not significant. When adding the difference in log disposable income of the siblings, the coefficient on household income does not change, but the own income effect is significantly positive.
} 
a smoker. If anything, the results we find here indicate the opposite. These findings can be reconciled with the theoretical model as developed by Dustmann and Windmeijer (1999), building on the Grossman (1972) model of health investment. In this model there is a clear distinction between permanent differences in health investment behaviour that are a related to differences in permanent income, and responses to transitory changes in income. In our analysis here, the permanent effects creates the observed inverse association between household income and smoking status of the children in the household, whereas the transitory income changes within household lead to more normal “consumption” type responses along the different consumption levels of the households.

\section{Conclusions}

We have analysed data from the British Household Panel Survey (BHPS) and British Youth Panel (BYP) to investigate the role of parental income on children's smoking prevalence. We establish that there is an inverse association between household socioeconomic status and children's smoking status with children in households with an income in the lower two quintiles more likely to smoke. This effect is attenuated when the mother's education is also included in the model, with a strong inverse relation between a mother's education and her children's smoking prevalence.

To investigate whether there is a possible direct causal effect from household income to a child's smoking behaviour we have looked at the relationship within household of differing smoking behaviour of siblings (at the same age) and changes in household income. We do not find that increases in household income decreases the probability of children's smoking, rather our estimation results suggest the opposite.

These results together suggest that children's lifestyles and health investments are correlated with parental income and that difference seems due to differences in permanent income. Transitory income changes do not necessarily lead to different behaviour.

\section{Bibliography}

Banks, J., L. Blow and F. Windmeijer (2005), Cigarette Taxes and Smoking Behaviour in the UK, mimeo, IFS. 
Brynin, M. (1999), Smoking Behaviour: Predisposition or Adaptation?, Journal of Adolescence, 22, 635 - 646.

DeCicca, P., D. Kenkel and A. Mathios (2002), Putting out the Fires: Will Higher Taxes Reduce the Onset of Youth Smoking?, Journal of Political Economy, 110, 144-169.

Department of Health (1998), Smoking Kills: A White Paper on Tobacco, London: The Stationery Office

Department of Health (2004), Drug Use, Smoking and Drinking Among Young People in England in 2003, London: The Stationery Office.

Department of Health (2004), Choosing Health: Making Healthy Choices Easier, London: The Stationery Office.

Dustmann, C. and F. Windmeijer (1999), Wages and the Demand for Health: A life Cycle Analysis, IFS Working Paper Series No. W99/20.

Ermisch, J., M. Francesconi and D.J. Pevalin (2001), The Outcomes for Children of Poverty, DWP Research Report 158, London: HMSO.

Garces, E., D. Thomas and J. Currie (2002), Longer Term Effects of Head Start, The American Economic Review, 92, 999-1012.

Griliches, Z., (1979), Sibling Models and Data in Economics: Beginnings of a Survey, Journal of Political Economy, 87, S37-S64.

Grossman, M., (1972), On the Concept of Health Capital and the Demand for Health, Journal of Political Economy, 80, 223-255.

Gruber, J. (2000), Youth Smoking in the US: Prices and Policies, NBER Working Paper Series no. 7506.

Ross, H., F.J. Chaloupka and M. Wakefield (2001), Youth Smoking Uptake Progress: Price and Public Policy Effects, ImpacTeen Research Paper Series no. 11, University of Illinois at Chicago.

Soteriades, E.S. and J.R. DiFranza (2003), Parent's Socioeconomic Status, Adolescents' Disposable Income, and Adolescents' Smoking Status in Massachusetts, American Journal of Public Health, 93, 1155-1160. 
Tyas, S. L. and L.L. Pederson (1998), 'Psychosocial Factors Related to Adolescent Smoking: a Critical Review of the Literature', Tobacco Control, 7, 409 - 420. 